\title{
Laparoscopic transabdominal preperitoneal versus open mesh lichtenstein repair of inguinal hernia: a comparative analysis
}

\author{
Akhtar M.S. ${ }^{1}$, Ali W.M. ${ }^{2}$, Khan T.A. ${ }^{3}$, Raza M.H. ${ }^{4}$, Ahmad M⿻ ${ }^{5}$, Sajid M $^{6}$ \\ ${ }^{1}$ Dr. Mohammad Sadik Akhtar, Assisstant Professor, ${ }^{2}$ Dr. Wasif Mohammad Ali, Assisstant Professor, ${ }^{3}$ Dr.Tausif Ahmed \\ Khan, Senior Resident, ${ }^{4}$ Dr. Mohammad Habib Raza, Professor, ${ }^{5}$ Dr. Manzoor Ahmad, Assisstant Professor, \\ ${ }^{6}$ Dr Mohammad Sajid, Junior Resident. All authors are affiliated with Department of Surgery, J.N.M.C.H, A.M.U, \\ Aligarh, UP, India.
}

Address for Correspondence: Dr. Mohammad Sadik Akhtar, Email: mohmdsadhiq@gmail.com

\begin{abstract}
Background: Inguinal hernia repair is a commonly performed surgery usually managed by open surgical mesh repair. Nowadays many patients are demanding laparoscopic hernia repair. Laparoscopic hernioplasty has a shorter rehabilitation, but it is a technically difficult procedure. It is unclear if it has advantages over open tension-free mesh repair. Methodology: This prospective study of 80 patients is done at Jawaharlal Nehru Medical College Hospital, A.M.U., Aligarh from January 2012 to November, 2014. 50 patients underwent Lichtenstein tension free mesh repair while on 30 patients TAPP was performed. Results: Out of 80 patients 7 patients were lost to follow up at 2 weeks. 47 patients in Lichtenstein group and 26 patients in TAPP group were followed for 6 months. Average operation time was $39.3 \pm 16.4$ minutes for the Lichtenstein group and 51.4 \pm 15.8 minutes for the TAPP group. Postoperatively, pain score was $6.5 \pm 3.5$ in lichtenstein group as compared to 5.8 \pm 1.5 in TAPP group. Because of lesser postoperative pain, the TAPP patients got significantly fewer analgesics than the Lichtenstein patients $(2.4 \pm 1.0)$ versus $(3.5 \pm 1.3)$ doses. TAPP patients needed significantly fewer admission days than Lichtenstein patients ( $2.5 \pm 0.6$ versus $1.8 \pm 0.5$ days, respectively). TAPP patients returned to work earlier as compared to Lichtenstein group (11.7 \pm 4.9 days versus $14.8 \pm 4.2$ days respectively). Short term and long complications were similar in both groups. Conclusion: Laparoscopic hernioplasty (TAPP) is superior to Lichtenstein tension-free hernioplasty in terms of postoperative pain, hospital stay and return to daily activity.
\end{abstract}

Keywords: Transabdominal Preperitoneal, Lichtenstein, Tissue repair, Laparoscopy, Numeric Pain Intensity Score

\section{Introduction}

Inguinal hernia is commonly encountered pathological problem by the surgeon in the surgical practice. Hernia surgery has undergone tremendous refinement in technique. Various methods have been advocated by different authors but each has got its own merits and demerits. The first safe and effective surgery was discovered by Professor Bassini of Italy in 1884 [1]. His recurrence rate was unheard of at the time and marked a distinct turning point in the evolution of herniorrhaphy [2]. The operation was considered the gold standard for inguinal hernia repair for most of the twentieth century [3]. The problem with these tissue repair methods is the tension placed upon the tissues which can lead to

Manuscript received $14^{\text {th }}$ June 2016

Reviewed: $26^{\text {th }}$ June 2016

Author Corrected: $11^{\text {th }}$ July 2016

Accepted for Publication $23^{\text {rd }}$ July 2016 recurrence. This led to the introduction of mesh repairs in an attempt to reduce wound tension. Lichtenstein popularised this technique and his repair was the first pure prosthetic, tension-free repair to achieve consistently low recurrence rates in long-term outcomes analysis [4]. A Lichtenstein tension free hernia repair operation has now become the method of choice in many centres around the world. The superiority of mesh repair was confirmed in a review conducted by the Cochrane group in conjunction with the European Hernia Trialists Collaboration [5].

Laparoscopic inguinal herniorrhaphy was introduced in the late 1980s by Ger in 1982, [6] and he pointed out its potential advantages like less postoperative pain, reduced recovery time allowing earlier return to full 
activity, easier repair of a recurrent hernia and the ability to treat bilateral hernias. Many detractors feel that these advantages are seldom met and point to the possibility of a laparoscopic accident resulting in a major complications and the need for a general anaesthesia. In addition, many surgeons are concerned about the expensive equipment needed.

They argue that the open operation can be performed under local anaesthesia on an outpatient basis, with minimal risk of intra-abdominal injury, and at less cost [3]. Today, most laparoscopic inguinal hernia repairs are performed with placement of a synthetic mesh into the preperitoneal space, which can be accomplished in one of two ways: the transabdominal preperitoneal (TAPP) approach or the totally extraperitoneal (TEP) approach [5].

A Cochrane review in 2003 showed recurrence rates for laparoscopic and open repair to be equivalent [7]. Besides recurrence rates, other important factors to consider are the duration of the operation, complication rates, length of hospital stay, time to return to usual activities, persisting pain and numbness and port site hernias. The same Cochrane review found that laparoscopic techniques had longer operating times of about 15 minutes, higher seroma formation incidence and higher incidence of vascular and visceral injuries like bladder, small bowel. It also showed lower incidence of haematomas, wound infection, and persisting pain and numbness and faster return to usual activities by seven days.

So comparing laparoscopic and open hernia repair techniques keeping in mind the primary goals of surgery like preventing strangulation, repairing the hernia, minimizing the chance of recurrence, returning the patient to normal activities quickly, and minimizing postsurgical discomfort and the adverse effects of surgery is essential. The various surgeries include a spectrum of benefits and risks, which presents some clinical uncertainty in the choice between approaches. Recurrence occurs in approximately 1 to 5 percent of cases [8]. Balancing all the factors e.g., recurrence, adverse events, time to return to work is a difficult yet critical process in making the best possible medical decisions.

In our study we have compared TAPP and Lichtenstein Tension Free Mesh repair in an attempt to answer the queries regarding selection of procedure and its outcomes in patients of inguinal hernia.

\section{Material and Methods}

This study is a prospective study, done on patients presenting to general-surgery OPD who were 18 years of age or older, had a diagnosis of inguinal hernia, gave written informed consent and were eligible for random assignment to Lichtenstein tension-free repair or laparoscopic repair at Jawaharlal Nehru Medical College Hospital, A.M.U., Aligarh, UP, India during the period, from January, 2012 to November, 2014.

Patients with unilateral inguinal hernia were included for comparative analysis. Patients in American Society of Anaesthesiologists (ASA) class IV (i.e., those who had systemic disease that is a constant threat to life) or class V (i.e., those who were unlikely to survive for 24 hours, with or without an operation) [9] were excluded, as were those who had contraindications to general anaesthesia, bowel obstruction, bowel strangulation, peritonitis, bowel perforation, local or systemic infection, contraindications to pelvic laparoscopy, a history of repair with mesh. After applying exclusion criteria a total of 80 patients were included in the study, 50 in open repair group (GROUP A) and 30 in TAPP group (GROUP B) allotted randomly.

All the patients underwent standardized repairs by a single operating team and the presence of the operating surgeon at the operating table throughout the procedure was required. The open procedure was performed according to the Lichtenstein method and laparoscopic repairs were performed by a transabdominal preperitoneal approach. All repairs involved the use of prolene mesh. All the patients were given standardized postoperative instructions that did not restrict their activities unless the activities caused pain.

Among the intraoperative factors, the following were evaluated: anaesthesia method (regional, general), and duration of the operation.

Prophylactic antibacterial treatment was used in all patients in the form of $1.5 \mathrm{~g}$ of cefuroxime was used intravenously during the operation. Preoperative and postoperative outcomes measured were : 


\section{Primary Outcome Measure:}

1. Recurrence Of Inguinal Hernia: The patients were followed for a minimum of six months. Postoperatively, each patient was examined at two weeks, at three months, and six months to determine the presence or absence of recurrence by a surgeon who had not been involved in that patient's operation. Recurrences were confirmed by clinical examination by an another surgeon and by ultrasound examination.

\section{Chronic/persistent groin pain (Inguinodynia);}

Post operative pain last for more than 3 months ( IASP* 1886)

*IASP= International Association for the Study of Pain

\section{Secondary Outcome Measures:}

\section{Early post operative pain:}

a. Pain persist on the second day of operation. Intensity of Post operative pain was assessed in terms of No pain, mild, moderate, severe, very severe, worst possible pain on the basis of Numeric Pain Intensity Scale (NPIS).

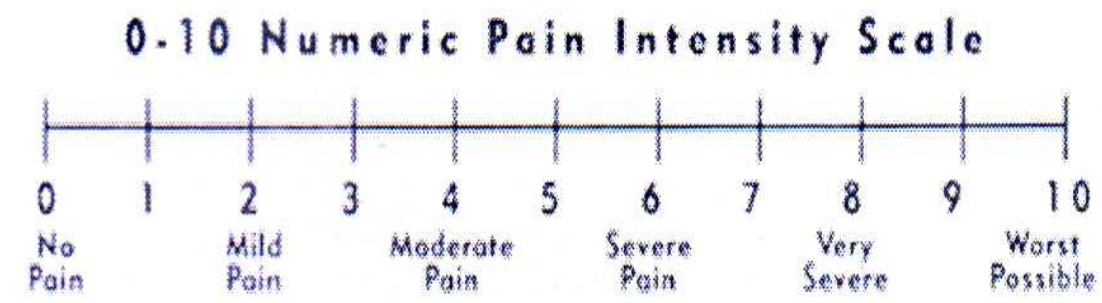

2. Post operative analgesia : For postoperative analgesia, $1 \mathrm{~mL}$ of $3 \%$ ketorolac was used. The number of ampoules and the dosage of analgesics were calculated.

3. Seroma: A seroma was defined as a non tender irreducible hemispherical swelling with a fluctuant or firm consistency at the hernia site.

4. Infection

5. Haematoma

6. Urinary retention

7. Days of admission

8. Return to work

9. Visceral / vascular injuries

10. Port-site hernia

11. Mortality (30 day mortality)

Statistical Analysis: The statistical analysis was conducted on the intention to treat basis. Numerical data was compared with the help of Unpaired t-test for continuous data and Chi square test for categorical data with large sample size (cell count $\geq 5$ ) and Fisher exact test for categorical data with small sample size ( cell count $<5$ ). p-value $>0.05$ proves the null hypothesis, that means there is no statistical difference between two groups. Between the groups with two tailed independent Student's t test was used. Analysis was done on SPSS version 23 for windows.

\section{Results}

In this study of 80 patients, preoperative data of all of them were analyzed. 3 patients from group A and 4 patients of group B were lost after $1^{\text {st }}$ follow up of 2 weeks. Complete preoperative and postoperative analyses of 73 patients were done. In 2 patients of group B (TAPP) group contralateral hernia was detected during surgery whose presence was not known preoperatively. Both groups were similar by preoperative factors (sex, age, laterality, body mass index, tobacco use, occupation, American Society of Anaesthesiologists risk groups, comorbidities,). No statistically significant differences were found between the groups by these factors (Table 1). 
Analysis of intraoperative factors and short term operative complications showed that there was a statistically significant difference $(\mathrm{P}<0.001)$ in use of type of anaesthesia as both group have different type of anaesthesia. This is explainable by the fact all 50 Lichtenstein operations were performed using regional anesthesia, whereas all TAPPs were done using general anaesthesia. Average operation time was 39.3 \pm 16.4 minutes for the Lichtenstein group and $51.4 \pm 15.8$ minutes for the TAPP group. TAPP operation time was higher in comparison with Lichtenstein time, and this difference is statistically significance ( $\mathrm{P}<0.001)$; Table 2 ). Regarding the postoperative factors, pain score was $6.5 \pm 3.5$ in lichtenstein group as compared to $5.8 \pm 1.5$ in TAPP group. The difference was statistically significant (P 0.002). Statistically significant difference was present between groups ( p 0.002) for the use postoperative analgesia. Because of postoperative pain, the TAPP patients got significantly fewer analgesics than the Lichtenstein patients $(2.4 \pm 1.0)$ versus $(3.5 \pm 1.3)$ doses, respectively. TAPP patients needed significantly fewer admission days than Lichtenstein patients $(2.5 \pm 0.6$ versus $1.8 \pm 0.5$ days, respectively; $\mathrm{P}<0.001)$. TAPP patients returned to work earlier as compared to lichtenstein group $(11.7 \pm 4.9$ days versus $14.8 \pm 4.2$ days respectively, $\mathrm{P}<0.001)$. Short term complications when compared there was no statistical difference between the groups. 2 patients developed haematoma in group A while no haematoma was seen in group B (p 0.48). 1 patient developed seroma in group A while 2 patients developed seroma in froup B (p 0.59). 3 patients developed infection of incision site in group A while 1 patient developed infection of port site in Group B( $p$ 0.64). Only 1 patient suffered urinary retention in group A while 3 patients had retention in group B (p 0.24). Although higher incidence of seroma formation and urinary retention in TAPP group encountered but difference was not significant. It is noticeable that in the TAPP group there was single case of visceral injury who had a urinary bladder rent but difference was not significant ( $\mathrm{p}$ 0.76). This case was converted to open procedure. In long term post operative factors there was 1 case of hernia recurrence observed during the follow-up in lichtenstein group while no patient had recuurence in TAPP group (p 0.45). At 6 months, 9 patients from the Lichtenstein group developed chronic pain ( 2 severe, 5 moderate, and 2 mild). At that time point, chronic pain had developed in 2 patients from the TAPP group (p 0.33). There was no 30 day mortality in any group. 1 patient in TAPP group developed port site hernia and was subsequently managed by open tissue repair.

Table- 1: Preoperative factors in two treatment groups ${ }^{\mathrm{a}}$

\begin{tabular}{|c|c|c|c|}
\hline Characteristics & Lichtenstein (group A) & TAPP (group B) & P value \\
\hline Sex & 46 & 28 & 0.82 \\
Male & 4 & 2 & 0.22 \\
Female & $48.2(5.9)$ & $49.7(5.8)$ & 0.91 \\
\hline Age (years) & $25(1.5)$ & $24.9(1.6)$ & 0.35 \\
\hline BMI kg/m $\mathrm{m}^{2}$ & 32 & 23 & 0.59 \\
\hline Laterality & 18 & 7 & 0.50 \\
Right & 21 & 10 & \\
Left & 35 & 18 & 0.51 \\
\hline Current smoker & 15 & 12 & 0.89 \\
\hline Occupation & & & 0.74 \\
\hline Light work & 9 & 3 & 0.32 \\
Heavy work & 13 & 9 & \\
\hline Comorbidities & 8 & 4 & \\
Cardiovascular & 18 & 12 & \\
Respiratory & 25 & 15 & \\
Diabetes & 7 & 3 & \\
\hline ASA risk group & & & \\
1 & & & \\
\hline
\end{tabular}

ASA, American Society of Anaesthesiologists; BMI, body mass index

a-Data are expressed as mean (SD) or absolute number of patients. 
Table-2: Intraoperative and short term operative complications ${ }^{\text {a }}$

\begin{tabular}{|c|c|c|c|}
\hline Characteristics & $\begin{array}{c}\text { Lichtenstein (group A) } \\
(\mathbf{n - 4 7 )}\end{array}$ & $\begin{array}{c}\text { TAPP (group B) } \\
\text { (n-26) }\end{array}$ & P value \\
\hline $\begin{array}{c}\text { Anaesthesia } \\
\text { Regional } \\
\text { General }\end{array}$ & 47 & 0 & $<\mathbf{0 . 0 0 1}$ \\
\hline Operative time (mins) & 0 & $51.4 \pm 15.8$ & $<\mathbf{0 0 1}$ \\
\hline Pain score & $39.3 \pm 16.4$ & $5.8 \pm 1.5$ & $\mathbf{0 . 0 0 2}$ \\
\hline Analgesia dose (no of \\
ampoules)
\end{tabular}

a-Data are expressed as mean (SD) or absolute number of patients

Table-3: Long term operative complications ${ }^{\mathrm{a}}$

\begin{tabular}{|c|c|c|c|}
\hline Characteristics & $\begin{array}{c}\text { Lichtenstein (group A) } \\
(\mathbf{n - 4 7 )}\end{array}$ & $\begin{array}{c}\text { TAPP (group B) } \\
\text { (n-26) }\end{array}$ & P value \\
\hline Recurrence & 1 & 0 & 0.45 \\
\hline $\begin{array}{c}\text { Chronic pain } \\
\text { 6 months }\end{array}$ & 9 & 2 & 0.33 \\
\hline 30 day mortality & 0 & 0 & - \\
\hline Port site herniax & 0 & 1 & - \\
\hline
\end{tabular}

a-Data are expressed as mean (SD) or absolute number of patients

*- only in TAPP group

\section{Discussion}

Ideal surgery for hernia repair would cause minimal problem to the patient, both while surgery and in the postoperative period. It would be technically easy to learn and simple to perform, would have a low rate of complications and recurrence, and would require only a short period of recovery period so that patient could return to his normal schedule of life. Until a few decades ago, the standard method for inguinal hernia repair were tissue repairs done by suturing fascial structures around the hernia defect, until Lichtenstein et al [10] introduced tension-free repair. It rapidly gained widespread recognition worldwide and surgeons mastered the technique in a short span of time.

With advances in minimal access surgery, the laparoscopic repair of inguinal hernia has been described using either a totally extraperitoneal or a transabdominal preperitoneal (TAPP) approach $[11,12]$.
Several research have established tension-free mesh repair as the gold standard in inguinal hernia repair [13]. Other studies have shown laparoscopic repair to be safe and efficient. It offers the patient the advantages of minimally invasive surgery and the associated recurrence rate does not differ from that of the classic open tension-free mesh technique. It can be used as a first-line option even for repair of unilateral primary inguinal hernias $[14,15,16]$.

Our study has shown that surgery time is shorter in the Lichtenstein group than in the TAPP group $(39.3 \pm 16.4$ vs $51.4 \pm 15.8$ respectively), although sample size of our study is small but this difference rose to significant level ( $\mathrm{p}<0.001$ ). Our data are similar to the data from several other investigations [7, 17, 18], although Eklund et al [19] found no difference in the operation time between the laparoscopic and Lichtenstein methods. 
Patients from the TAPP group are characterized by significantly fewer episodes of postoperative pain ( $p$ 0.002), and as a consequence lower use of analgesic drugs ( $P$ 0.002), less sick-leave days, faster recovery and early return to work ( $\mathrm{p}<0.001$ ). The patients who underwent TAPP also had a fewer admission days as compared to Lichtenstein repair group ( $p<0.001)$. The same advantages of the laparoscopic method in comparison with the Lichtenstein approach are documented also by other authors [7, 17, 18, 19, 20]. Short term operative complications like haematoma, seroma, infection and urinary retention were similar in both groups and there were no differences found. Authors of some previous studies have shown that laparoscopic methods are characterized by fewer postoperative complications than Lichtenstein operations [18, 19]. Based on their investigations, Neumayer et al [20] came to the conclusion-that open surgical interventions have fewer postoperative complications than laparoscopy. Schmedt et al [17] conducted a meta-analysis in which they showed that wound infection and hematoma are less frequent in cases of endoscopic surgery, whereas seroma is less frequent in cases of the Lichtenstein method.

Our data on the structure of the postoperative complications show that frequencies of wound complications (infection, hematoma, seroma) are almost equal in both groups. No statistically, significant difference was found even for urinary retention (3 versus 1 for TAPP and Lichtenstein, respectively; P 0.24). Z. Demetrashvili et al [21] reported a significant difference in incidence of urinary retention in patients undergoing TAPP. The Schmedt et al [17] metaanalysis and data from several other randomized trials indicate that this complication is equally frequent for both methods [18, 20]. Different pattern in our study can be explained by the fact that all laparoscopic operations were done under general anesthesia, whereas for the Lichtenstein approach, all operations were performed using regional anaesthesia. The impact of general anaesthesia on the development of urinary retention is reviewed by Jensen et al [22] who found low incidence of urinary retention with local anaesthesia as compared to regional and general anaesthesia.

In our study only 1 patient had a recurrence in Lichtenstein group while no recurrences occured in TAPP group. The patient who suffered recurrence was markedly underweight, active smoker and had a respiratory problem which could explain recurrence.
Chronic pain incidence was statistically similar in both groups and there was no significant difference. By this factor our investigation corresponds to the data by Eklund et al [19], although it should be mentioned that larger studies have shown that laparoscopic methods are characterized by fewer chronic pain episodes than instances of Lichtenstein approach [7, 17].

There were no incidences of 30 day mortality but a single port site hernia in TAPP group.

Study done by Tamme (2003) [23] in a large group of 5203 patients, who underwent laparoscopic hernioplasty showed no incidence of port site hernia However an incidence of $0.7 \%$ of port site hernia was reported by Fitzgibbons (1995) [24] in a group of 686 patients undergoing laparoscopic hernioplasty. No incidence of mortality in a study done by Mir et al (2015) [25] is in tune with our study.

\section{Conclusion}

We conclude that laparoscopic hernia surgery is better than Lichtenstein repair in terms of less postoperative pain, less analgesia during recovery and an earlier discharge and return to daily work hence higher patient satisfaction. As far as learning curve of laparoscopy is concerned, with training and experience it is not a problem. If there are any contraindications for the laparoscopy, Lichtenstein repair should be operation of choice.

Funding: Nil, Conflict of interest: None initiated, Permission from IRB: Yes

\section{References}

1. Thorwald J. Bassini. The Triumph of Surgery. 1st ed. Great Britain: Jarold\& Sons; 1960. p.274-299.

2. Javid PJ, Brooks DC. Hernias. In: Zinner MJ, Ashley SW, editors. Maingot's Abdominal Operations. 11th ed. USA: The McGraw-Hill Companies, Inc.; 2007. p. 103.

3. Fitzgibbons RJ, Filipi CJ, Quinn TH. Inguinal Hernias. In: Brunicardi FC, Andersen DK, BilliarTR, Dunn DL, Hunter JG, Pollock RE, editors. Schwartz's Principles of Surgery. 8th ed. USA:The McGraw-Hill Companies, Inc.; 2005. p. 1354.

4. Kingsnorth AN, Britton BJ, Morris PJ. Recurrent inguinal hernia after local anaesthetic repair. Br J Surg. 1981 Apr;68(4):273-5. 
5. Scott NW, McCormack K, Graham P, Go PM, Ross SJ, Grant AM. Open mesh versus non-mesh for repair of femoral and inguinal hernia. Cochrane Database Syst Rev. 2002;(4):CD002197.

6. Ger R. The management of certain abdominal herniae by intra-abdominal closure of the neck of the sac. Preliminary communication. Ann R Coll Surg Engl. 1982 Sep;64(5):342-4.

7. McCormack K, Scott NW, Go PM, Ross S, Grant AM; EU Hernia Trialists Collaboration. Laparoscopic techniques versus open techniques for inguinal hernia repair. Cochrane Database Syst Rev. 2003;(1): CD 001785

8. Sherwinter DA, Lavotshkin S. Hernia inguinal repair, open: treatment \& medication. eMedicine. Updated 2009 Jul 24. http://emedicine.medscape. com/article/ 1534281-treatment. Accessed January 26, 2011.

9. Dripps RD. New classification of physical status. Anesthesiol. 1963;24:111.

10. Lichtenstein IL, Shulman AG, Amid PK, Montllor MM. The tension-free hernioplasty. Am J Surg. 1989 Feb;157(2):188-93

11. Hope WW, Bools L, Menon A, Scott CM 3rd, Adams A, Hooks WB 3rd. Comparing laparoscopic and open inguinal hernia repair in octogenarians. Hernia. 2013 Dec; 17(6):719-22. doi: 10.1007/ s10029-0121013-3. Epub 2012 Nov 7.

12. Symeonidis D, Baloyiannis I, Koukoulis G, Pratsas K, Georgopoulou S, Efthymiou M, Tzovaras G. Prospective non-randomized comparison of open versus laparoscopic trans abdominal preperitoneal (TAPP) inguinal hernia repair under different anesthetic methods. Surg Today. 2014 May; 44(5):906-13. doi: 10.1007/s 00595-013-0805-0. Epub 2013 Dec 7.

13. Perko Z, Rakic M, Pogorelic Z, Družijanic N, Kraljevic J. Laparoscopic transabdominal preperitoneal approach for inguinal hernia repair: a five-year experience at a single center. Surg Today 2011 Feb; 41(2): 216-221. DOI: $10.1007 / \mathrm{s} 00595-010-4266-4$

14.Tzovaras G, Symeonidis D, Koukoulis G, Baloyiannis I, Georgopoulou S, Pratsas C, Zacharoulis D. Long-term results after laparoscopic transabdominal preperitoneal (TAPP) inguinal hernia repair under spinal anesthesia. Hernia. 2012 Dec;16(6):641-5. doi: 10.1007/s10029-012-0934-1. Epub 2012 Jun 24.
15. Eklund AS, Montgomery AK, Rasmussen IC, Sandbue RP, Bergkvist LA, Rudberg CR. Low recurrence rate after laparoscopic (TEP) and open (Lichtenstein) inguinal hernia repair: a randomized, multicenter trial with 5-year follow-up. Ann Surg. 2009 Jan;249(1):33-8. doi: 10.1097/SLA.0b013e31819255d0.

16. Oguz H, Karagulle E, Turk $\mathrm{E}^{1}$, Moray G. Comparison of peritoneal closure techniques in laparoscopic transabdominal preperitoneal inguinal hernia repair: a prospective randomized study. Hernia. 2015 Dec; 19(6) : 879-85. doi: 10.1007/ s10029-0151431-0. Epub 2015 Oct 20.

17. Schmedt CG, Sauerland S, Bittner R. Comparison of endoscopic procedures vs Lichtenstein and other open mesh techniques for inguinal hernia repair: a meta-analysis of randomized controlled trials. Surg Endosc. 2005 Feb;19(2):188-99. Epub 2004 Dec 2.

18. Dedemadi G, Sgourakis G, Karaliotas C, Christofides T, Kouraklis G, Karaliotas C. Comparison of laparoscopic and open tension-free repair of recurrent inguinal hernias: a prospective randomized study. Surg Endosc. 2006 Jul;20(7):1099-104. Epub 2006 Jun 8.

19. Eklund A, Rudberg C, Leijonmarck CE, Rasmussen I, Spangen L, Wickbom G, Wingren U, Montgomery A. Recurrent inguinal hernia: randomized multicenter trial comparing laparoscopic and Lichtenstein repair. Surg Endosc. 2007 Apr;21(4):634-40. Epub 2007 Feb 16.

20. Neumayer L, Giobbie-Hurder A, Jonasson O, Fitzgibbons R Jr, Dunlop D, Gibbs J, Reda D, Henderson W; Veterans Affairs Cooperative Studies Program 456 Investigators. Open mesh versus laparoscopic mesh repair of inguinal hernia. N Engl J Med. 2004 Apr 29;350(18):1819-27.Epub 2004 Apr 25.

21. Demetrashvili Z, Qerqadze V, Kamkamidze G, Topchishvili G, Lagvilava L, Chartholani T, Archvadze V. Comparison of Lichtenstein and laparoscopic transabdominal preperitoneal repair of recurrent inguinal hernias. Int Surg. 2011 Jul-Sep;96(3):233-8.

22. Jensen P, Mikkelsen T, Kehlet H. Postherniorrhaphy urinary retention--effect of local, regional, and general anesthesia: a review. Reg Anesth Pain Med. 2002 NovDec;27(6):612-7. doi: 10.1053/rapm.2002.37122.

23. Tamme C, Scheidbach H, Hampe C, Schneider C, Köckerling F. Totally extraperitoneal endoscopic inguinal hernia repair (TEP). Surg Endosc. 2003 
Feb;17(2):190-5. Epub 2002 Dec 4. doi 10.1007/ s00464-002-8905-8.

24. Fitzgibbons RJ Jr, Camps J, Cornet DA, Nguyen NX, Litke BS, Annibali R, Salerno GM. Laparoscopic inguinal herniorrhaphy. Results of a multicenter trial. Ann Surg. 1995 Jan;221(1):3-13.
25. Mir IS, Nafe AA, Malyer AA, Nafe M, watali Y, Farooq M, Bhat SB, Viqar S. An Experience of ShortTerm Result of Laparoscopic Inguinal Hernioplasty Using 3D Mesh in a Developing Country. IJCM 2015 Jan;6:64-69.doi 10.4236/ijcm.2015.61010.

\section{How to cite this article?}

Akhtar M.S., Ali W.M., Khan T.A., Raza M.H., Ahmad M, Sajid M. Laparoscopic transabdominal preperitoneal versus open mesh lichtenstein repair of inguinal hernia: a comparative analysis. Int J Med Res Rev 2016;4 (7):11991206.doi:10.17511/ijmrr.2016.i07.21. 